\title{
Peripheral locked in syndrome following snake envenomation - a case report
}

\author{
Sweta Kumari Gupta ${ }^{1}$, Bhabani Kanta Sarmah ${ }^{2}$, Amshu Shakya Bajracharya ${ }^{3}$ \\ ${ }^{1}$ Lecturer, ${ }^{2}$ Professor and HOD, ${ }^{3}$ Junior resident, Department of Pediatrics, College of Medical Sciences, \\ Bharatpur, Chitwan district, Nepal.
}

\section{Correspondence \\ Dr. Sweta Kumari Gupta \\ College of Medical Sciences, \\ Bharatpur, Nepal \\ Email: \\ doctorsweta84@gmail.com}

DOI: http://dx.doi.org/10.3126/ jcmsn.v11i4.14323

\begin{abstract}
Snake bite is a terror in the Terai regions of Nepal. It is estimated that at least 20,000 snake bites occur each year with about 1000 deaths in hospitals, mainly in the Terai region. About $25 \%$ of the total snake bite cases constitute children in the endemic regions of snakes. Majority of children (85\%) following snakebite envenomation develop local or systemic complications. They present in varied ways, from a stable patient with no symptoms to a completely paralyzed child with all features of brain death present, although for a brief time. This has been termed locked in syndrome in snake bite. The locked in syndrome describes patients who are awake and conscious but selectively differenced, i.e., have no means of producing speech, limb or facial movements. If not detected early, it is not uncommon for children presenting with locked in syndrome being put to funeral pyre or buried alive. Sometimes there might not be bite mark making the diagnosis even more challenging. A two year old boy presented with restlessness and quadriparesis following neurotoxic snake envenomation. Later he developed complete paralysis with most features of brain death present like absent dolls eye, absent corneal reflexes and a dilated and fixed pupil only two hours following the bite. He was treated with a standard regimen of anti-snake venom (ASV) along with other supportive measures. His remarkable recovery with the above treatment points towards the necessity of recognizing this syndrome in children following snake bite and continuing all supportive therapies till they regain their reflexes and powers.

Key words: Anarthia, locked in syndrome (LIS), neurotoxic snake bite.
\end{abstract}

Citation: Gupta SK, Sarmah BK, Bajracharya AS. Peripheral locked in syndrome following snake envenomation - a case report. JCMS Nepal. 2015;11(4):32-34.

\section{INTRODUCTION}

Snake bite is a common hazard in terai region of Nepal. It is most common in the monsoon season, in the months of June to September. ${ }^{1}$ In Nepal, the common species of snakes seen are the Elapidae which includes cobra and krait, viperidae which includes Russell's viper. In the Terai region of Nepal, a community-based study established the high fatality rate of 161/100000/year, attributable mainly to krait bites. ${ }^{2}$ The peak age groups for snake bites is children and young adults. There is some evidence that peak case fatality is in young children and the elderly. ${ }^{3}$ Early morning neuroparalytic syndrome or peripheral locked in syndrome is a rare presentation of elapid bite. ${ }^{4}$

\section{THE CASE}

A 2 years old boy presented to the casualty of
COMS-TH after one hour of snake bite. Child had restlessness and abdominal pain. It was rapidly followed by difficulty in breathing and quadriparesis. Physical examination at the emergency room revealed a gasping child with a Glasgow Coma Scale of $6 / 15$, bilateral reactive pupils, bilateral ptosis and paresis of limbs. His heart rate was 120/min, blood pressure 120/80 $\mathrm{mmHg}$; SpO2 was only $65 \%$ in room air. Fang marks were present in the right palm without evidence of local envenomation.

A provisional diagnosis of neuroparalytic snake envenomation (Krait) was made. Endotracheal intubation was done and ASV was immediately started in infusion. Child was then shifted to the Pediatric Intensive Care Unit (PICU) and attached to mechanical ventilator. At 6:20am, four hours after the bite, examination revealed fixed mid - 
dilated pupil, $4 \mathrm{~mm}$ in size and a GCS of 3/15, Dolls eye reflex were absent along with corneal reflexes. His vitals were maintained and urine output was adequate. He received 30 vials of polyvalent anti snake venom. Other supportive treatments were continued. After 20 hours of receiving $\mathrm{ASV}$, child had bilateral constricted pupils $2 \mathrm{~mm}$ in size but GCS was still 3/15 without any sedation. Child remained unresponsive without any improvement for up to 38 hours of admission. And then initial sign of recovery was sluggishly reacting pupils noticed after 24 hours of ASV. Ptosis started improving from day three along with the power of his upper limbs (2/5). Deep tendon reflexes were present by day four. Child had spontaneous movement of upper limbs by day five. Gradually on day six, child had a power of $3 / 5$ of lower limbs as well. Same day child was successfully weaned off of ventilator. Minimal lower limb weakness persisted at the time of transfer to the pediatric ward on day seven. Child was freely ambulating by day eight and was discharged on day nine. The child was too young to recall the events during LIS so we could not retrieve any information about his consciousness during the period of LIS.

\section{DISCUSSION}

Locked-in syndrome (LIS) is characterized by total paralysis and anarthria in a conscious patient. Locked-in syndrome has been classified into three categories: Classic - Quadriplegia and anarthria with preserved consciousness and vertical eye movement. Incomplete-The same as classic but with remnants of voluntary movement other than vertical eye movement. Total-Total immobility and inability to communicate, with full consciousness. ${ }^{5}$ Central LIS, the more commonly encountered form is due to lesions in ventral pons. 5 Recently described are the peripheral causes of LIS, severe acute polyneuropathy, neuromuscular junction blockade (myasthenia gravis, toxins) and snake bites. Knowledge about the peripheral cause of LIS is very vital, as one may make an erroneous diagnosis of brain death in LIS. ${ }^{6,7}$ Confirmatory tests like electroencephalography, cerebral blood flow, nerve conduction velocities are recommended to avoid a misdiagnosis of coma or brain death. ${ }^{8}$

Elapid neurotoxicosis acts at the peripheral neuromuscular junctions either post-synaptically by binding competitively at acetylcholine receptors like cobra or pre-synaptically by preventing the release of acetylcholine from the nerve terminals like kraits. ${ }^{3}$ Paralysis is first detected as bilateral ptosis and external ophthalmoplegia progressing to involve the muscles of the palate, jaw, tongue, neck and deglutition. Generalized flaccid paralysis may result with consciousness provided the patient is not in circulatory failure. ${ }^{4}$ Irreversible binding of toxin to presynaptic portion makes clinical recovery slow in krait envenomation as recovery occurs only with the formation of new neuromuscular junctions, which could be the cause in our case. ${ }^{9}$

Recently there has been few case reports of total peripheral locked in syndrome in children following snake envenomation from different parts of India. Dr. Mohd. Haneef ${ }^{4}$ has described a similar occurrence in a 14 year old female child as early morning neuroparalytic syndrome. Azad et $\mathrm{al}^{9}$ has illustrated total locked in syndrome in four Indian children of varied age groups. In this study, the duration of LIS varied from 30 hours to six days. Varadarajan et a ${ }^{10}$ has separately reported a case of peripheral locked in syndrome in a four year old girl. To the best of author's knowledge, so far no such case has been reported in children in Nepal.

\section{CONCLUSION}

Peripheral locked in syndrome following snake envenomation has an astounding recovery. So all treating pediatricians should know that snake envenomation can present with unresponsive but conscious and non-communicable state. They should be able to differentiate it from brain death. Whether with history of snake bite or not, any child with sudden onset of flaccid paralysis of unknown cause should be given a benefit of doubt and treated with ASV. The propensity of survival is almost 100 percent if properly managed. Our patient has given an invaluable gift of experience to all of us which we have tried to share with all our readers.

\section{REFERENCES}

1. Shrestha BM. Outcome of snake envenomation in children. J Nepal Paediatr Soc. 2011;31(3):192-7. DOI:10.3126/ jnps.v31i3.5358.

2. Paudel KM, Sharma S. Study of clinico-epidemiological profile and outcome of snake bite in children. J Nepal Paediatr Soc. 2012;32(1):47-52. DOI:10.3126/ jnps.v32i1.5948.

3. Warrell DA. Guidelines for the management of snake bites. New Delhi: WHO, Regional Office for South-East Asia; 2010.

4. Hanef M. George DE, Babu AS. Early morning neuroparalytic syndrome. Indian J Padiatr. 2009;76 
(10):1072

DOI:10.1007/s12098-009-0210-2;

PMID:19907949.

5. Smith E, Delargy M. Locked-in syndrome. BMJ. 2005:330 (7488);406-9.

DOI:10.1136/bmj.330.7488.406; PMID:15718541; PMCID:PMC549115.

6. Laureys S, Pellas F, Van Eeckout P, Ghorbel S, Schnakers C, Perrin F, et al. The Locked in Syndrome: What is it like to be a conscious but paralyzed and voiceless? Prog Brain Res. 2005; 150:495-511. DOI:10.1016/S0079-6123(05) 50034-7; PMID:16186044.

7. Prakash S, Mathew $C$, Bhagat S. Locked in syndrome in snake bite. J Assoc Physicians India. 2008; 56:121-2. PMID:18472515.

8. Thomas A, Ashwal S, Mudit M, Mohan R, Bruce D, Conway EE, Jr., et al. Guidelines of determination of brain death in infants and children: An update of the 1987 task force recommendations. Crit Care Med. 2011;39(9):2139$55 . \quad$ DOI:10.1097/CCM.0b013e31821f0d4f; PMID:21849823.

9. Azad C, Mahajan V, Jat RK. Locked in syndrome as presentation in snake bite. Indian Paediatric journal. 2013;50(7):695-7. DOI:10.1007/s13312-013-0174-1. PMID:23942434.

10. Varadarajan P, Sankaralingam T, Sangareddy SPJ. Peripheral locked - in syndrome following snake envenomation. Pediatric Oncall [Internet] 2013 Aug [cited 2013 August 1];10(8). Available from: http:// www.pediatriconcall.com/Journal/Article/FullText.aspx? artid $=570 \&$ type $=J \&$ tid $=\&$ imgid $=\&$ reportid $=28 \&$ tbltype $=$. DOI:10.7199/ped.oncall.2013.41. 